\title{
Haplogroup $\mathrm{J}$ mitogenomes are the most sensitive to the pesticide rotenone: Relevance for human diseases
}

\author{
Daniela Strobbe ${ }^{\mathrm{a}}$, Leonardo Caporali ${ }^{\mathrm{b}}$, Luisa Iommarini ${ }^{\mathrm{c}}$, Alessandra Maresca ${ }^{\mathrm{b}}$, \\ Monica Montopoli $^{\mathrm{a}}$, Andrea Martinuzzi ${ }^{\mathrm{d}}$, Alessandro Achilli ${ }^{\mathrm{e}}$, Anna Olivieri ${ }^{\mathrm{e}}$, Antonio Torroni ${ }^{\mathrm{e}}$, \\ Valerio Carelli ${ }^{\mathrm{b}, \mathrm{f}, *}$, Anna Ghelli ${ }^{\mathrm{c}, * *}$ \\ a Department of Pharmaceutical and Pharmacological Sciences, School of Medicine-University of Padua, Italy \\ ${ }^{\mathrm{b}}$ IRCCS Institute of Neurological Sciences of Bologna, Bologna, Italy \\ ${ }^{\mathrm{c}}$ Department of Pharmacy and Biotechnology (FABIT), University of Bologna, Bologna, Italy \\ d IRCCS "E. Medea" Scientific Institute Conegliano-Pieve di Soligo Research Center, Pieve di Soligo, Italy \\ e Dipartimento di Biologia e Biotecnologie "L. Spallanzani", University of Pavia, Pavia, Italy \\ ${ }^{\mathrm{f}}$ Department of Biomedical and NeuroMotor Sciences (DIBINEM), University of Bologna, Bologna, Italy
}

\section{A R T I C L E I N F O}

\section{Keywords:}

Rotenone

Cybrids

Mitochondrial DNA

Haplogroups

Complex I

\begin{abstract}
A B S T R A C T
There is growing evidence that the sequence variation of mitochondrial DNA (mtDNA), which clusters in population- and/or geographic-specific haplogroups, may result in functional effects that, in turn, become relevant in disease predisposition or protection, interaction with environmental factors and ultimately in modulating longevity.

To unravel functional differences between mtDNA haplogroups we here employed transmitochondrial cytoplasmic hybrid cells (cybrids) grown in galactose medium, a culture condition that forces oxidative phosphorylation, and in the presence of rotenone, the classic inhibitor of respiratory Complex I. Under this experimental paradigm we assessed functional parameters such as cell viability and respiration, ATP synthesis, reactive oxygen species production and mtDNA copy number.

Our analyses show that haplogroup $\mathrm{J} 1$, which is common in western Eurasian populations, is the most sensitive to rotenone, whereas $\mathrm{K} 1$ mitogenomes orchestrate the best compensation, possibly because of the haplogroup-specific missense variants impinging on Complex I function. Remarkably, haplogroups J1 and K1 fit the genetic associations previously established with Leber's hereditary optic neuropathy (LHON) for J1, as a penetrance enhancer, and with Parkinson's disease (PD) for $\mathrm{K} 1$, as a protective background.

Our findings provide functional evidences supporting previous well-established genetic associations of specific haplogroups with two neurodegenerative pathologies, LHON and PD. Our experimental paradigm is instrumental to highlighting the subtle functional differences characterizing mtDNA haplogroups, which will be increasingly needed to dissect the role of mtDNA genetic variation in health, disease and longevity.
\end{abstract}

\section{Introduction}

The human mitochondrial genome (mtDNA) is a multicopy circular molecule of 16,569 base pairs (bp) in length (Andrews et al. 1999), which encodes 13 key proteins for oxidative phosphorylation (OXPHOS) as well as 22 tRNA and two rRNA genes, needed for mtDNA expression and translation, due to the slightly different genetic code from nuclear DNA (nDNA) (Schon et al. 2012; Gustafsson et al. 2016). Proteins carrying out mtDNA replication, transcription and translation, as most of the proteins needed to build mitochondria are instead encoded in the nDNA, with about 1500 proteins composing the nuclear mitoproteome (Calvo et al. 2016). The mtDNA is strictly maternally inherited, follows non-Mendelian transmission rules (Schon et al. 2012; Gustafsson et al. 2016) and is characterized by a high mutation rate, which introduces continuously new variants that, at least initially, coexist in the cell with the original sequence (heteroplasmy) (Payne et al. 2013). When the new variants affect the germline, they might be inherited, often after having gone through bottlenecks. Therefore, they

* Correspondence to: V. Carelli, IRCCS Institute of Neurological Sciences of Bologna (ISNB), Bellaria Hospital, Neurology Unit, Department of Biomedical and Neuromotor Sciences (DIBINEM), University of Bologna, Via Altura 3, 40139 Bologna, Italy.

** Correspondence to: A. Ghelli, Dipartimento di Farmacia e Biotecnologie (FABIT), Università degli studi di Bologna, Via Selmi 3, 40126 Bologna, Italy.

E-mail addresses: valerio.carelli@unibo.it (V. Carelli), annamaria.ghelli@unibo.it (A. Ghelli). 
sometimes reach homoplasmy becoming fixed in a new mtDNA haplotype, or might be lost, leaving only the original genome sequence (Stewart and Chinnery 2015). Variants with functional effect on OXPHOS efficiency may undergo selection, with climate and diet being proposed as major driving forces (Mishmar et al. 2003; Ruiz-Pesini 2004). Some variants have a clear pathogenic effect on OXPHOS function, and indeed a long catalog of mtDNA pathogenic mutations has been compiled in the three decades since the first finding (Ruiz-Pesini et al. 2007; http://www.mitomap.org/), affecting the most energy-dependent cells and tissues, such as neurons in peripheral and central nervous systems, and leading to a large variety of diseases (DiMauro et al. 2013; Carelli and Chan 2014).

The sequence variation of mtDNA has been extensively employed to study human origin and patterns of population dispersal, lending support to the "out of Africa" model (Vigilant et al. 1991; Soares et al. 2010). Furthermore, because of its potential role in adaptation, as suggested by the rapid evolution of its sequence and the functional interplay with the environment, the consequences of different mtDNA haplotypes and mutations have been also assessed extensively in human ageing and pathology (Larsson 2010; Wallace 2015). Unfortunately most of the reported associations between mtDNA haplogroups and diseases have suffered of poor reproducibility, being frequently underpowered and with a biased composition of controls (Samuels et al. 2006; Raule et al. 2007). Among the most solidly established and reproduced associations is the one between mtDNA haplogroup $\mathrm{J}$, as a penetrance modulator, and Leber's hereditary optic neuropathy (LHON) (Carelli et al. 2006; Hudson et al. 2007). LHON is a neurodegenerative mitochondrial disease leading to optic nerve atrophy due to pathogenic mtDNA point mutations affecting Complex I genes (Carelli et al. 2004). Interestingly, a recent metanalysis of mtDNA haplogroup studies in Parkinson disease (PD), an age-related neurodegenerative disorder also characterized by Complex I deficiency, revealed that haplogroups $\mathrm{J}, \mathrm{K}$ and T might exert a protective role (Hudson et al. 2013). Haplogroup J has also been associated with successful ageing in centenarians (De Benedictis et al. 1999). Thus, the emerging paradox is that the same set of polymorphic missense variants, affecting Complexes I and III and characterizing specific sub-branches of haplogroup J (Pala et al. 2012), may lead to very different outcomes (Wallace 2013).

Only a few studies have tried to unravel the subtle functional differences between mtDNA haplogroups, often employing the cybrid cell model that allows the comparison of different mtDNAs on the same nuclear background (King and Attardi 1989). In LHON cybrids, haplogroup $\mathrm{J}$ has been shown to modulate Complex I stability (Pello et al. 2008) and sensitivity to toxins such as solvents (Ghelli et al. 2009). Furthermore, control cybrids carrying haplogroup $\mathrm{J}$ displayed reduced mtDNA amount and defective OXPHOS when compared with haplogroup H (Gómez-Durán et al. 2012).

We here revisited this issue testing the sensitivity of haplogroup $\mathrm{J}$ mitogenomes to the pesticide rotenone, a classic inhibitor of complex I, that has been implicated in PD pathogenesis (Betarbet et al. 2000) and is frequently used to model complex I deficiencies such as LHON (Marella et al. 2010).

\section{Material and methods}

\subsection{Cell lines and culture conditions}

The eleven transmitochondrial cytoplasmic hybrids (cybrids) were generated by fusion of enucleated fibroblasts, obtained after informed consent from skin biopsies of unrelated control subjects with a "normal" mitogenome (i.e. without any known pathological mutation), with osteosarcoma (143.TK-)-derived 206 cells, deprived of their own mtDNA (King and Attardi 1996). Cybrids were grown at $37^{\circ} \mathrm{C}$ in Dulbecco's modified Eagle's medium (DMEM-high glucose) supplemented with $10 \%$ fetal bovine serum (FBS) (South America source from Gibco, Invitrogen, Italy), $2 \mathrm{mM}$ L-glutamine, $100 \mathrm{U} / \mathrm{ml}$ penicillin, $100 \mu \mathrm{g} / \mathrm{ml}$ streptomycin, in an incubator with a humidified atmosphere of $5 \% \mathrm{CO}_{2}$.

\subsection{MtDNA sequence variation, haplogroup affiliation and complex I modeling}

The mitogenome sequences of the three novel cybrids (H28705, HF16W and HAD) were determined as previously reported (Torroni et al. 2001), while the other eight were already published (Achilli et al., 2005; Ghelli et al. 2009; Pala et al. 2012; Pello et al. 2008; Perli et al., 2012). Haplogroup affiliations were defined according to PhyloTree (www.phylotree.org, mtDNA tree Build 17; van Oven and Kayser 2009). Pathogenicity predictions were performed by Mitimpact 2.7 (mitimpact.css-mendel.it). The positioning of the amino acid changes in the 3D Complex I structure was determined using UCSF Chimera 1.11.2 (www.cgl.ucsf.edu/chimera/) on the entire ovine respiratory Complex I (Fiedorczuk et al. 2016; PDB file 5LNK).

\subsection{Cell viability}

Viability was determined using the colorimetric sulforhodamine B (SRB) assay (Scarlatti et al. 2003). Cells were seeded (30.000 per well) in DMEM-high glucose and after $24 \mathrm{~h}$ incubated in DMEM glucose-free medium supplemented with $5 \mathrm{mM}$ galactose, $5 \mathrm{mM}$ Na-pyruvate and $5 \%$ FBS (DMEM galactose medium) in presence or absence of 10, 20 and $40 \mathrm{nM}$ rotenone. Cellular viability was assessed after $24 \mathrm{~h}$ by SRB assay. Absorbance was measured at $540 \mathrm{~nm}$ by using a microplate reader [VICTOR ${ }^{3}$ Multilabel Plate Counter (PerkinElmer Life and Analytical Sciences, Zaventem Belgium)]. The SRB absorbance value in the absence of rotenone corresponds to $100 \%$ viable cells.

\subsection{Oxygen consumption and rotenone titration}

Oxygen consumption rate (OCR) in glucose medium was measured in adherent cells with an XF24 Extracellular Flux Analyzer (Seahorse Bioscience, Billerica, MA, USA). Briefly, cells were seeded in XF24 cell culture microplates (Seahorse Bioscience) at $2 \times 10^{4}$ cells/well in $250 \mu \mathrm{l}$ of complete high glucose medium and incubated at $37^{\circ} \mathrm{C}$ in $5 \%$ $\mathrm{CO}_{2}$ for $24 \mathrm{~h}$. The assay began the following day according to the manufacturer's instructions by replacing the growth medium in each well with $525 \mu$ l of unbuffered DMEM-medium supplemented with $10 \mathrm{mM}$ glucose, $5 \mathrm{mM}$ pyruvate, and $1 \mathrm{mM}$ glutamine pre-warmed at $37^{\circ} \mathrm{C}$. Cells were incubated at $37^{\circ} \mathrm{C}$ for $60 \mathrm{~min}$ to allow temperature and $\mathrm{pH}$ equilibration. After an OCR baseline measurement, $75 \mu \mathrm{l}$ of medium containing oligomycin $(1 \mu \mathrm{M})$ were added to each well to obtain the value of oxygen consumption derived by proton leak. The third OCR measurement was performed adding $75 \mu \mathrm{l}$ of medium containing $1 \mu \mathrm{M}$ FCCP to obtain the maximal rate of oxygen consumption and finally, $75 \mu \mathrm{l}$ of medium containing rotenone and antimycin A (both $1 \mu \mathrm{M})$ were added to completely inhibit respiratory chain. At the end of the experiment, respiration rates were normalized for the protein cell content in each well using the colorimetric sulforhodamine B assay. The experiments in galactose medium were performed seeding cells in XF24 cell culture microplates at $3 \times 10^{4}$ cells/well in $250 \mu$ l of galactose medium at $37^{\circ} \mathrm{C}$ in $5 \% \mathrm{CO}_{2}$ for $24 \mathrm{~h}$. The following day the growth medium was replaced in each well with $525 \mu \mathrm{l}$ of unbuffered DMEMmedium supplemented with $5 \mathrm{mM}$ galactose, $5 \mathrm{mM}$ pyruvate and $1 \mathrm{mM}$ glutamine and the experiment was carried out exactly as described above but using galactose medium for each addition.

The rotenone titration was assessed in $10 \mathrm{mM}$ glucose medium and after an OCR baseline measurement, the microplates were divided in four group and rotenone titration was performed adding to each group of wells $75 \mu \mathrm{l}$ of medium containing $0 ; 2.5 ; 5 ; 10 \mathrm{nM}$ rotenone respectively and the residual OCR was measured. Then, oligomycin $(1 \mu \mathrm{M})$ was added to each well to obtain the value of oxygen consumption derived by proton leak, and after the maximal rate of oxygen consumption was measured in presence of $1 \mu \mathrm{M}$ FCCP. Finally, rotenone 
and antimycin A (both $1 \mu \mathrm{M}$ ) were added to completely inhibit respiratory chain. At the end of the experiment, respiration rates were normalized for cell content in each well using the colorimetric sulforhodamine B assay. Data were expressed as percentage of residual respiration relative to untreated cells.

\subsection{ATP synthesis assay}

The assay of mitochondrial ATP synthesis driven by complex I or complex II substrates was determined in digitonin-permeabilized cybrid cell lines, exactly as previously described in the luciferin/luciferase assay (Manfredi et al. 2002), with minor modifications (Giorgio et al. 2012). Protein content and citrate synthase activity were also measured as previously detailed by (Bradford 1976) and (Trounce et al. 1996), respectively. The residual activity of ATP synthesis after incubation of rotenone $10 \mathrm{nM}$ in galactose medium for $24 \mathrm{~h}$ was expressed as percentage of the activity in untreated cells.

\subsection{Reactive oxygen species (ROS) production}

ROS production was determined using 2',7'-dichlorodihydrofluorescein diacetate ( $\left.\mathrm{H}_{2} \mathrm{DCFDA}\right)$ as described by (Porcelli et al. 2010), with modifications. Cells were seeded $(40.000$ cells/well) and incubated in Hepes Ringer Solution Medium [ $\mathrm{NaCl} 125 \mathrm{mM}$, KCl $5 \mathrm{mM}$, $\mathrm{MgSO}_{4} 1 \mathrm{mM}, \mathrm{KH}_{2} \mathrm{PO}_{4} 1 \mathrm{mM}$, Hepes $20 \mathrm{mM}, \mathrm{CaCl}_{2} 1.3 \mathrm{mM}$, Galactose $5 \mathrm{mM}\left(\mathrm{pH} \mathrm{7,4)]} \mathrm{at} 37^{\circ} \mathrm{C}\right.$ in an incubator with a humidified atmosphere of $5 \% \mathrm{CO}_{2}$. The medium was supplemented with Calcein-AM $100 \mu \mathrm{M}$ and $\mathrm{H}_{2}$ DCFDA $2 \mu \mathrm{M}$. After 30 min cells were incubated with rotenone at a final concentration of 10 and $20 \mathrm{nM}$ for $2 \mathrm{~h}$ and $4 \mathrm{~h}$. Fluorescence was determined at $485 \mathrm{~nm}$ (excitation wavelength) and $535 \mathrm{~nm}$ (emission wavelength) using a multilabel plate reader $\left[\right.$ VICTOR $^{3}$ Multilabel Plate Counter (PerkinElmer Life and Analytical Sciences, Zaventem Belgium)].

\subsection{Mitochondrial DNA copy number quantification}

Absolute quantification of mtDNA relative to nDNA was performed by real-time PCR using a LightCycler ${ }^{\circledast} 480$ (Roche Applied Science, Penzberg, BY, DE). This method is a multiplex assay based on hydrolysis probe chemistry: 10-50 ng of DNA extracted from cells was adequate. Briefly, a mitochondrial DNA fragment (MT-ND2 gene) and a nuclear DNA fragment (FASLG gene) were co-amplified in a multiplex polymerase chain reaction and concentrations were determined by absolute quantification. Primers, probes and conditions were previously published (Mussini et al. 2005).

\subsection{SDS-PAGE and western blotting}

Cellular lysates were obtained solubilising about $3 \times 10^{6}$ of cells in $0.1 \mathrm{ml}$ of lysis buffer (1\% Triton-X-100, $0.5 \mathrm{mM}$ EDTA, $0.6 \mathrm{mM}$ PMSF, $100 \mu \mathrm{l} / \mathrm{ml}$ of protease inhibitor cocktail dissolved in phosphate buffered saline at $\mathrm{pH} 7.4$ ), sonicated and centrifuged at $10000 \times \mathrm{g}$. The protein content of the supernatant (cell lysate) was determined according to Bradford (Bradford 1976) and $60 \mu \mathrm{g}$ of proteins were separated by $12 \%$ SDS-PAGE. Gels were transferred onto nitrocellulose membrane (BioRad) for $1 \mathrm{~h}$ at $100 \mathrm{~V}$. The nitrocellulose membranes were incubated overnight at $4{ }^{\circ} \mathrm{C}$ with the indicated antibody. Primary antibodies were visualized using horseradish peroxidase-conjugated secondary antibodies (1:2000). The chemiluminescence signals were revealed using an ECL Western blotting kit (Amersham Bioscience, Buckinghamshire, UK) and measured with Gel Logic 1500 Imaging System, Kodak.

\section{Statistical analysis}

Statistical analyses were performed using GraphPad Prism 7 software, choosing the most appropriate test. Statistical significance was declared at $p \leq 0.05$. Comparisons between haplogroups were performed via Anova One Way followed by Bonferroni Test. Data are presented as means \pm SEM.

\section{Results}

\subsection{Cybrid generation and characterization of their mitogenomes}

We employed the well-established cell model for mtDNA functional studies known as transmitochondrial cytoplasmic hybrids or "cybrids", which has the advantage to assess possible differences amongst mtDNAs belonging to various haplotypes and/or haplogroups in a constant nuclear background. Our eleven cybrids were generated from enucleated fibroblast cell lines of healthy individuals. Eight cybrid cell lines were established and previously characterized (see methods), while three (H28705, HF16W and HAD) are new (Fig. 1 and Supplementary Table 1). The phylogenetic relationships of the eleven mitogenomes are shown in Fig. 1 as well as their GenBank accession numbers. Their haplogroup affiliations are according to PhyloTree (www.phylotree. org; van Oven and Kayser 2009). The most divergent mitogenome is H28705, a member of macro-haplogroup N, while all others cluster into six major sub-branches of the macro-haplogroup R: haplogroups $\mathrm{H}$ (HF16W and HAD), J (HQB, HGA and HFG), T (H42 and HPS), K (HP27 and HF01M) and U (HGDA), all typical of western Eurasian populations. The missense variants characterizing the cybrid mitogenomes are shown on the tree branches (Fig. 1), whereas their predicted functional impact is detailed in Supplementary Table 1.

\section{2. mtDNA backgrounds and viability of cybrids after treatment with rotenone}

The mtDNA haplogroup sensitivity to the pesticide rotenone, a classic inhibitor of Complex I (Degli Esposti 1998), was investigated by determining the concentration-dependent effect on cell viability after $24 \mathrm{~h}$ incubation in galactose medium. This is a well-established biochemical strategy to force cells using OXPHOS (Robinson 1996; Ghelli et al. 2003), thus highlighting the potential functional differences that may occur in relation to haplogroup-dependent variability. We first evaluated the global rotenone effect on cell viability grouping the eleven cybrids into the six major haplogroup branches N1b, H1, J, T, U and $\mathrm{K} 1$ of Fig. 1, observing that cell lines harboring haplogroup $\mathrm{J}$ mitogenomes were the most sensitive to the toxic effect of rotenone and showed a significant loss of viability compared to those belonging to haplogroups $\mathrm{H} 1$ and $\mathrm{K} 1$ (Fig. 2A). The same analysis was further stratified for each sub-haplogroup branch (N1b, H1, J1, J2, T1, T2, U, K1) showing that sub-haplogroup $\mathrm{J} 1$ had significantly higher sensitivity relative to $\mathrm{H} 1$ and $\mathrm{K} 1$ after incubation with rotenone (Fig. 2B). The results for each individual cybrid clone, including in some cases multiple cell lines from the same sub-haplogroup branch (two for J1 and two for K1), are shown in Supplementary Fig. 1. Overall, our observations show that mitochondrial backgrounds modulate sensitivity to rotenone toxicity when cells are forced to use OXPHOS.

\subsection{Haplogroup $H 1$ is the most resistant to rotenone effect on mitochondrial bioenergetics}

Next, we assessed rotenone sensitivity directly on cell respiration to investigate whether mitochondrial respiratory chain inhibition was related to the cell viability results. For these and further experiments, we selected only cybrids clones bearing haplogroups H1, J1 and K1 mitogenomes, which showed significant differences on cell viability after incubation with rotenone (Fig. 2B). First, we measured the mitochondrial OCR at basal, olygomycin inhibited (proton leak) and uncoupled conditions (FCCP or maximal respiration rate) in intact cybrids. Fig. 3A shows the OCR values measured after incubation in respiratory 


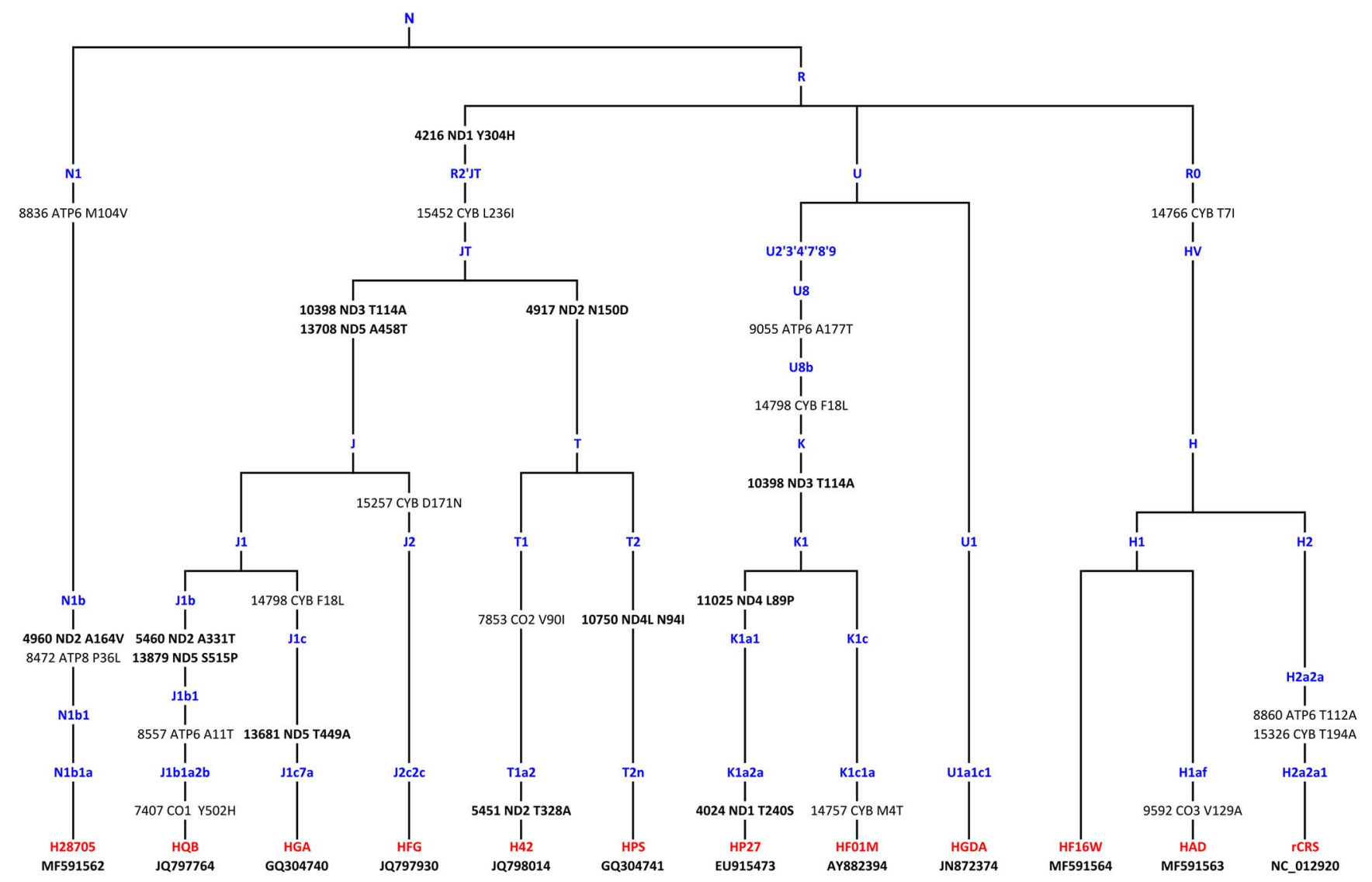

Fig. 1. Phylogenetic tree encompassing the cybrid mitogenomes used for the functional investigations.

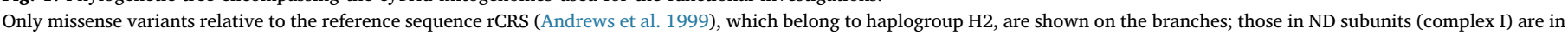

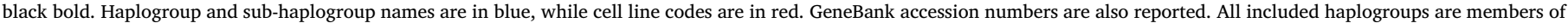
macro-haplogroup N. (For interpretation of the references to colour in this figure legend, the reader is referred to the web version of this article.)

glucose medium usually recommended by the manufacturer's assay conditions. This medium contains $10 \mathrm{mM}$ instead of $25 \mathrm{mM}$ glucose normally present in the growing medium DMEM high glucose. In this experimental condition, cells are able to maintain glycolysis and to activate cellular respiration, making the oxygen consumption mostly dependent on NADH-linked substrates (Wu et al. 2007). Our data show that there are not significant functional differences between OCR values from cybrids with mitogenomes belonging to haplogroups H1, J1 and K1. Furthermore, we also measured the OCR after $24 \mathrm{~h}$ incubation in galactose medium to investigate whether there were any differences in basal respiration, proton leak or uncoupled respiration. Fig. 3B shows that the basal OCR in galactose medium was significantly higher for haplogroup J1compared to haplogroups $\mathrm{H} 1$ and $\mathrm{K} 1$. These results indicate that, in galactose medium, haplogroup $\mathrm{J} 1$ is able to further activate respiration compared to haplogroups $\mathrm{H} 1$ and $\mathrm{K} 1$. In addition, we observed that, in galactose medium, the uncoupler FCCP did not stimulate respiration in any cell line, probably because substrate transport is partially affected, being mitochondrial carriers dependent on membrane potential. In fact, it has been already reported that, in intact cells, when mitochondria are completely depolarized, the substrate mitochondrial intake could became the rate limiting step for respiration (Divakaruni et al. 2014). Thus, to carefully measure the rotenone concentration that yielded $50 \%$ inhibition of maximal oxygen consumption rate ( $I_{50}$ rotenone), we preferred to use the experimental condition with glucose $10 \mathrm{mM}$ medium. Fig. 3C shows that haplogroups $\mathrm{J} 1$ and $\mathrm{K} 1$ had a similar $\mathrm{I}_{50}$ for rotenone $\left(\mathrm{I}_{50}-3 \mathrm{nM}\right)$, whereas haplogroup H1 was significantly less sensitive to rotenone inhibition $\left(\mathrm{I}_{50}-7 \mathrm{nM}\right)$ compared to haplogroups $\mathrm{J} 1$ and $\mathrm{K} 1$, suggesting that rotenone resistance of cell viability in haplogroup $\mathrm{H} 1$ could be partially due to a limited sensitivity of Complex I towards this drug. In addition, the
Seahorse assessments provided also further information on cell metabolism. Fig. 3D shows the Extra Cellular Acidification Rate (ECAR) of haplogroups $\mathrm{H} 1, \mathrm{~J} 1$ and $\mathrm{K} 1$ at basal conditions in glucose or galactose medium. In glucose medium, cells carrying haplogroup J1 showed ECAR values significantly higher compared to haplogroup H1, similar to haplogroup K1. Conversely, in galactose medium, haplogroup J1 showed ECAR values higher then both haplogroups $\mathrm{H} 1$ and K1. In glucose medium, the ECAR values are dependent on activation of both glycolysis and Kreb's cycle pathways, whereas in galactose medium ECAR values depend mostly on Kreb's cycle (Divakaruni et al. 2014). Thus, our results in glucose indicate that glycolysis and/or Kreb's cycle are more active in haplogroups $\mathrm{J} 1$ and $\mathrm{K} 1$ compared to haplogroup H1. Differently, in galactose the highest ECAR values for haplogroup J only suggests a prevalent aerobic metabolism compared to haplogroup K1, which probably supports ATP synthesis mostly by enhanced glycolysis.

We then measured the mitochondrial ATP synthesis driven by NADH-linked substrates (through Complex I) and by succinate (through Complex II) in permeabilized cells after $24 \mathrm{~h}$ incubation in galactose medium, with $10 \mathrm{nM}$ rotenone. In this way, we aimed to asses not only the direct inhibition of OXPHOS by rotenone but also the damage induced by this pesticide on mitochondrial efficiency during prolonged inhibition of Complex I. Fig. 3E shows that ATP synthesis driven by Complex I was inhibited similarly in all haplogroups, whereas the ATP synthesis driven by Complex II tended to be more affected in haplogroup J1 compared to $\mathrm{K} 1$ and $\mathrm{H} 1$, without reaching significance. The same results shown in Fig. 3 are also shown in Supplementary Fig. 2, but displaying each individual cybrid clone to provide an overview of the single clone behavior. Taken together these results indicate that haplogroups $\mathrm{J} 1$ and $\mathrm{K} 1$ are both more sensitive to Complex I inhibition by rotenone compared to haplogroup H1, but haplogroup K1 possibly 
A

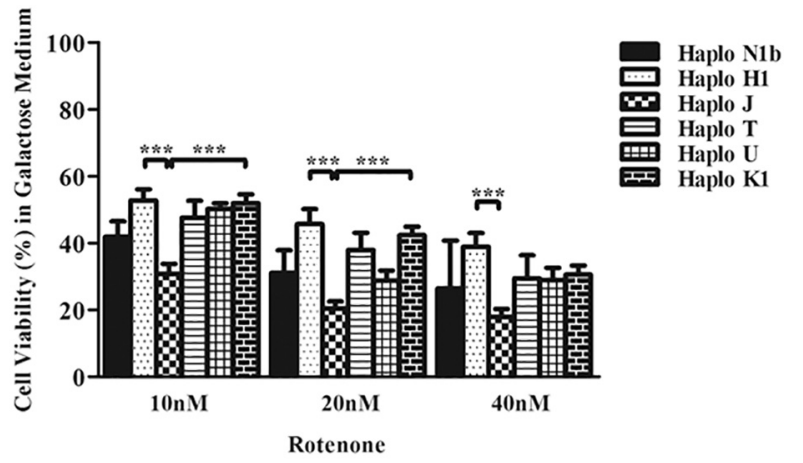

B
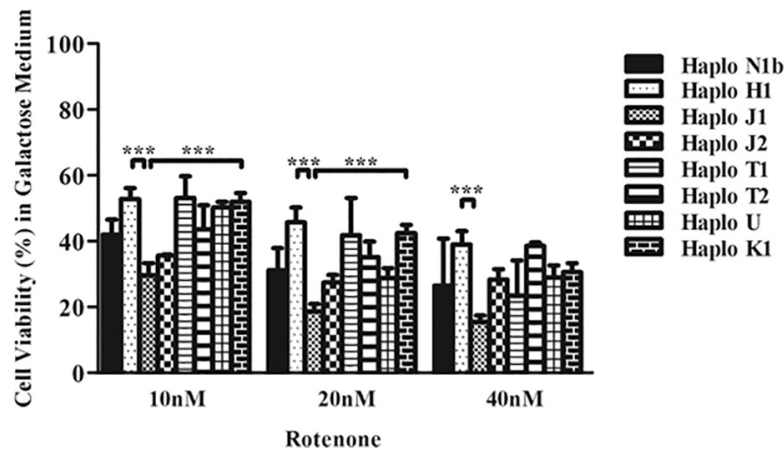

Fig. 2. Effect of rotenone on the viability of cybrids incubated in galactose medium with rotenone for $24 \mathrm{~h}$

(A) Cybrids are grouped according to major haplogroup clusters (N1b, H, J, T, U, K). (B) Cybrids are shown individually according to the sub-haplogroup classification (N1b, H1, $\mathrm{J} 1, \mathrm{~J} 2, \mathrm{~T} 1, \mathrm{~T} 2, \mathrm{U}, \mathrm{K} 1$ ). Data are presented as percentage of viable cells relative to nontreated cells. Values are expressed as mean \pm SEM $\left(4<n<10\right.$; $\left.{ }^{* * *} p<0,001\right)$.

maintains ATP levels also in presence of rotenone by enhancing glycolysis.

\subsection{Effect of rotenone on oxidative stress and mitochondrial biogenesis}

It has been reported that there is a Complex I-induced increase in ROS production after rotenone exposure (Koopman et al. 2010). Hence, we measured the production of $\mathrm{H}_{2} \mathrm{O}_{2}$ in cybrids carrying $\mathrm{H} 1, \mathrm{~J} 1$ and $\mathrm{K} 1$ mitogenomes after incubation in galactose medium with $10 \mathrm{nM}$ rotenone for $4 \mathrm{~h}$. As expected (Floreani et al. 2005), the shift from glucose to galactose medium significantly increased $\mathrm{H}_{2} \mathrm{O}_{2}$ production. Despite the addition of rotenone failed to further enhance ROS production in all cell lines grown in galactose medium, haplogroup K1 displayed the lowest ROS production (Fig. 4A and Supplementary Fig. 3A). To better understand whether these slight differences in ROS production depend on mitochondrial ROS scavenging by antioxidant enzymes, the expression levels of catalase and Peroxiredoxin 3 (PRX3) were assessed. Fig. 4B shows no differences for the cytosolic enzyme catalase amongst the different clones and treatments, whereas the mitochondrial PRX3 expression was sensitive to the different culture conditions. In particular, halogroup H1 and J1 cell lines showed an increased PRX3 expression after $24 \mathrm{~h}$ incubation in galactose and galactose plus10nM Rotenone medium, as compared to glucose medium, whereas haplogroup K1 showed similar high expression levels in all three conditions. Overall, these results indicate that the incubation in galactose and galactose plus rotenone induces an oxidative stress in mitochondria that may be counteracted by the expression and activity of PRX3, ultimately avoiding the increase of hydrogen peroxyde in cytosol, as documented by the $\mathrm{H}_{2}$ DCFDA experiments.

It has been previously suggested that ROS production is balanced by activation of mitochondrial biogenesis (Moreno-Loshuertos et al. 2006). Thus, we tested the effect of prolonged exposure to rotenone on mitochondrial biogenesis by assessing mtDNA copy number. Fig. 4C and Supplementary Fig. 3B show that haplogroup K1 cells had the highest mtDNA copy number, significantly different from both $\mathrm{H} 1$ and $\mathrm{J} 1$ cells, after $24 \mathrm{~h}$ incubation with galactose medium. This difference persisted after $24 \mathrm{~h}$ incubation with the addition of $10 \mathrm{nM}$ rotenone in the galactose medium, compared to untreated cells. Furthermore, we analyzed the expression levels of representative respiratory complexes subunits in the different conditions. Fig. 4D shows an increased expression of complex IV subunit COXII, and partially of CI subunit NDUFB8, in all cell lines when switching culture conditions from glucose to galactose, suggesting a slight increase of mitochondrial mass. Overall, this experiment did not highlight difference amongst haplogroups, failing to closely parallel the mtDNA copy number results.

4.5. Modeling of the polymorphic non-synonymous amino acid variants in ND subunits on the ovine Complex I crystal

Compared to haplogroup H1, haplogroups J1 and K1 harbor specific amino acid variants, due to non-synonymous mutations, in mtDNAencoded Complex I ND subunits, that might be relevant to its function. To dissect the correlation between rotenone sensitivity and haplogroups, we analyzed the recently released crystallographic structure of mammalian Complex I (Fiedorczuk et al. 2016) positioning those amino acids changed by these polymorphic ND subunit variants (Fig. 5). We limited our analysis to the diagnostic amino acid variants of the haplogroups, i.e. those shared by all its members, given that the others are more recent private variants characterizing only one of the two cybrids with the same (H1 and K1) affiliation (Fig. 1).

Haplogroup H1, which is the most insensitive to rotenone, and haplogroup $\mathrm{J} 1$, which instead is the most sensitive to rotenone toxicity by combining cell viability and mitochondrial bioenergetic experiments, differ at three nucleotide positions in ND genes (Supplementary Table 1) relative to the $\mathrm{R}$ root (Fig. 1). These three substitutions cause the amino acid changes p.Y304H (MT-ND1), p.T114A (MT-ND3) and p.A458T (MT-ND5) (Fig. 5A and B) in the cybrids harboring haplogroup $\mathrm{J}$ mitogenomes. The p.Y304H (MT-ND1) and p.T114A (MT-ND3) variants are close to the ND1 residues implicated in the quinone binding site for which rotenone competes (Fiedorczuk et al. 2016), while the third variant (p.A458T in MT-ND5) is far away from that site. Finally, haplogroup K1, which displayed sensitivity to rotenone titration that was similar to that of $\mathrm{J} 1$, but maintaining cell viability, only harbors the p.T114A (MT-ND3) variant, the same present in the haplogroup J1 mitogenomes (Fig. 5C).

\section{Discussion}

This study shows that the sequence variation of mitogenomes plays a role in cell viability of cybrids under culture conditions of forced OXPHOS and further exposed to the Complex I inhibitor rotenone. Under these experimental conditions, haplogroup J1 is the most sensitive to rotenone and the viability of $\mathrm{J} 1$ cybrids is significantly reduced. Conversely, our functional testing of cybrids revealed that haplogroup $\mathrm{H} 1$ is the most resistant to the toxic effect of rotenone and haplogroup $\mathrm{K} 1$ has the most efficient mitochondrial biogenesis as suggested by mtDNA copy number assessment. Congruently, haplogroups $\mathrm{H} 1$ and $\mathrm{K} 1$ cybrids are also the most resistant to rotenone challenge in terms of cell viability.

The ND amino acid variants distinguishing these haplogroups, when placed in the Complex I crystallographic model, highlight interesting differences and stimulate some possible considerations. While haplogroup H1, with no ND variants, displays the highest rotenone resistance, haplogroup J1 harbors two variants (p.Y304H/MT-ND1 and p.T114A/MT-ND3) at positions that might interfere with rotenone binding and the coenzyme $\mathrm{Q}$ binding pocket in the ND1 subunit 
A

Glucose

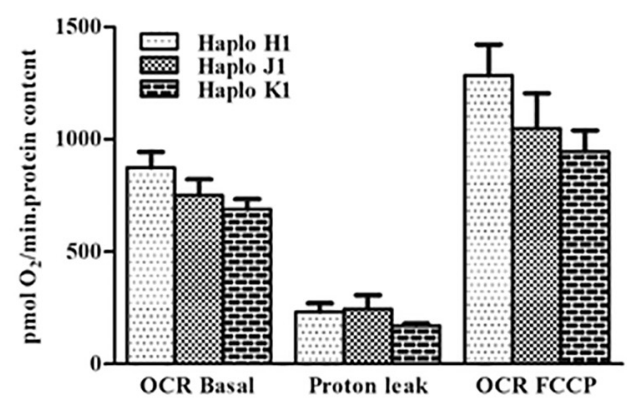

C

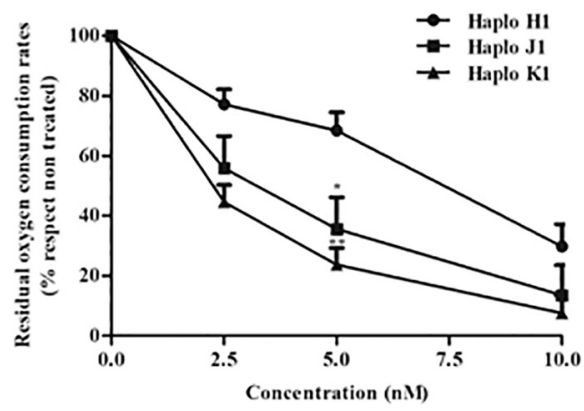

B

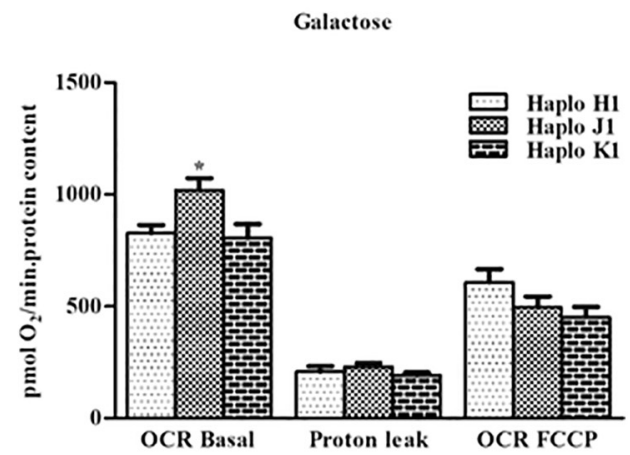

$\mathbf{D}$

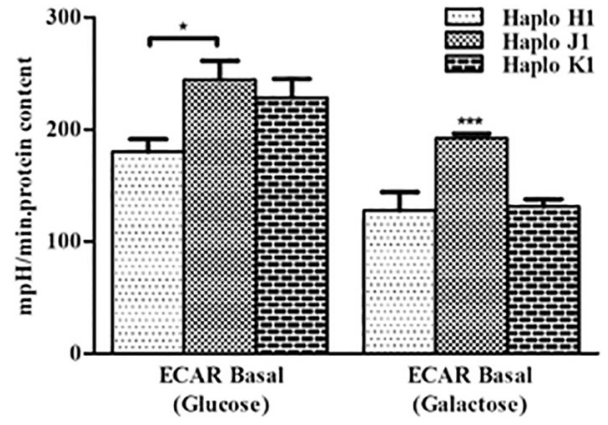

$\mathbf{E}$

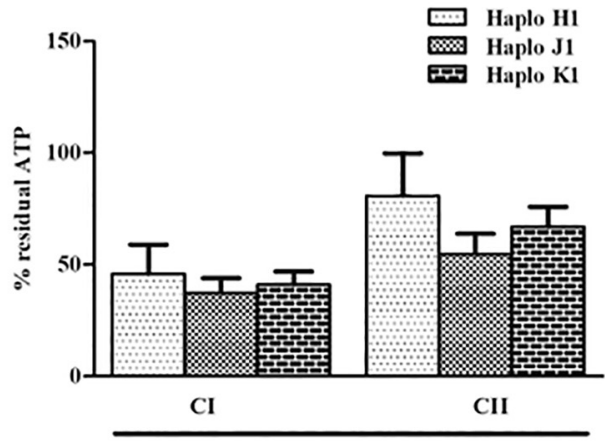

Rotenone 10nM

Fig. 3. Cellular OCR and ECAR profile in glucose and galactose medium and effect of rotenone.

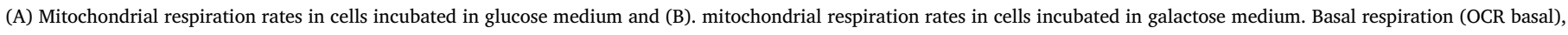

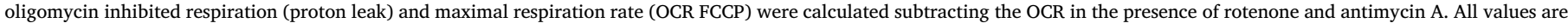
normalized for cellular content measured by SRB assay. Data are reported as mean \pm SEM $\left(7<n<8\right.$; $\left.{ }^{*} p<0.05\right)$.

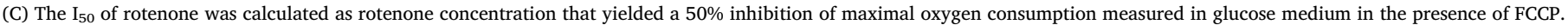
Data are reported as mean $\pm \operatorname{SEM}\left(4<n<6\right.$; $\left.{ }^{*} \mathrm{p}<0.05\right)$.

(D) ECAR values in basal conditions both in glucose and galactose medium. Data are reported as mean \pm SEM $(7<\mathrm{n}<8$; **0.001 $<p<0.01$; *p $<0.05)$.

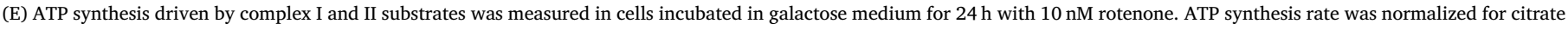
synthase activity. Data are reported as mean \pm SEM $(3<\mathrm{n}<10$; no variance was observed).

(Fiedorczuk et al. 2016). Interestingly, haplogroup K1, similarly sensitive to rotenone as haplogroup $\mathrm{J} 1$, also possesses the p.T114A/ND3 variant, pointing to this as the most relevant residue in modulating rotenone sensitivity. Remarkably, at the highest rotenone concentration of $40 \mathrm{nM}$, haplogroup J1 remained the most sensitive in terms of cell viability as compared to all other cybrids. At this stage we cannot rule out the possibility that the additional private ND variants characterizing the J1 cybrids (p.A331T/ND2 and p.S515P/ND5 in HQB; p.T449A/ND5 in HGA) might have further enhanced the sensitivity to rotenone and more generally the functional features of these cells.
These results corroborate on the functional ground the previously reported genetic associations of haplogroup $\mathrm{J}$ with LHON as a penetrance enhancer (Torroni et al. 1997; Carelli et al. 2006; Hudson et al. 2007), and of haplogroup K with PD as a protective background (Ghezzi et al. 2005; Hudson et al. 2013).

LHON has an established and well-reproduced association with haplogroup $\mathrm{J}$ for two (m.11778G $>\mathrm{A} / \mathrm{MT}-\mathrm{ND} 4$ and m.14484T $>\mathrm{C}$ / MT-ND6) of the three main pathogenic mutations, which is interpreted as a modifying genetic background enhancing penetrance (Torroni et al. 1997; Carelli et al. 2006; Hudson et al. 2007). Our findings 
A
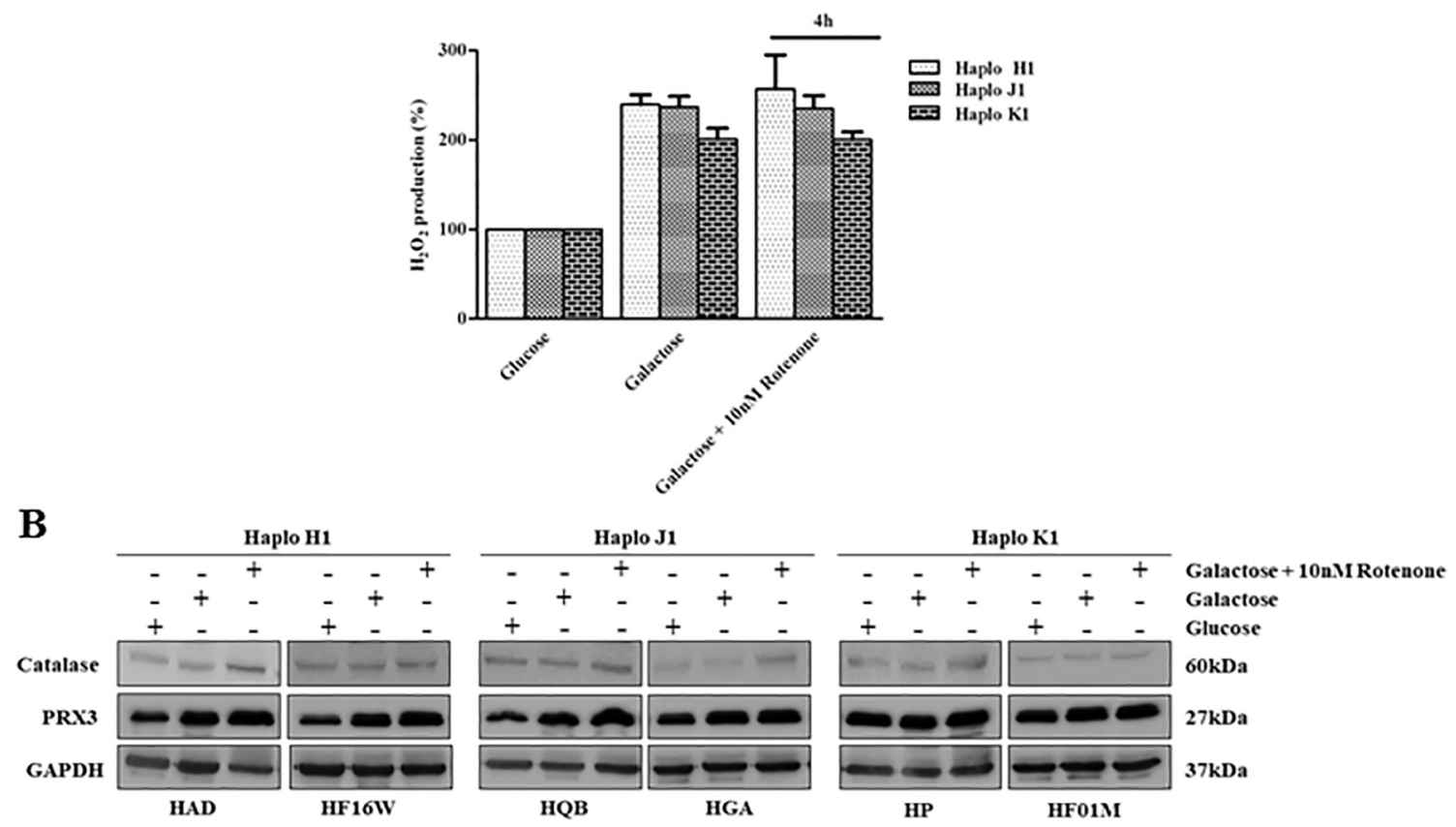

C

D
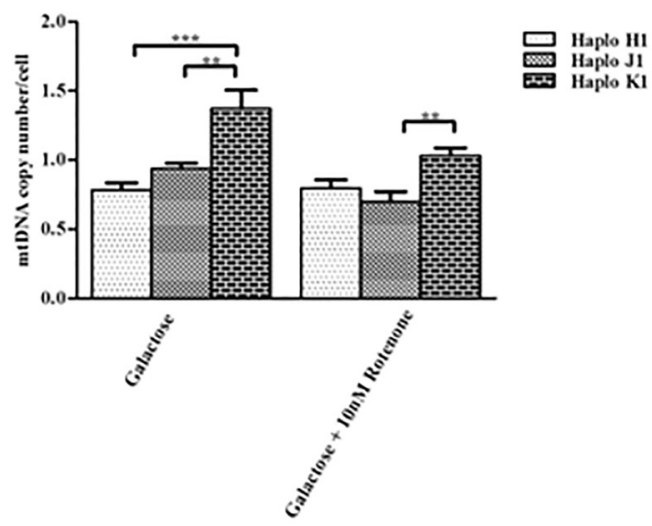
E⿹丁口 Haplo K1
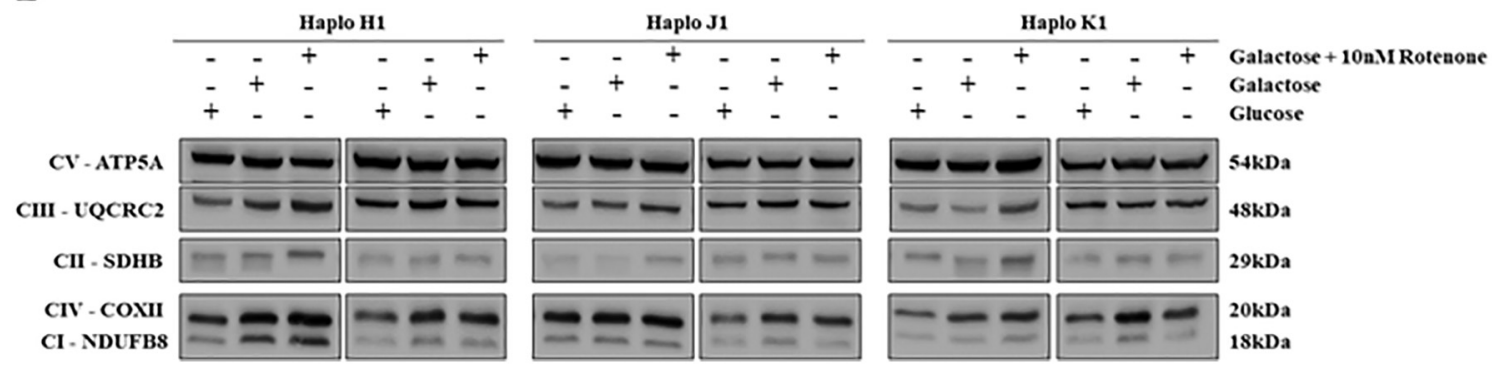

Fig. 4. Effect of rotenone on oxidative stress and mitochondrial biogenesis in cybrids with $\mathrm{H} 1$, J1 and $\mathrm{K} 1$ mitogenomes.

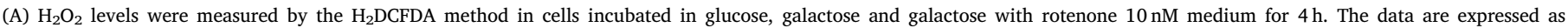
mean \pm SEM $(5<\mathrm{n}<10$; no variance was observed $)$

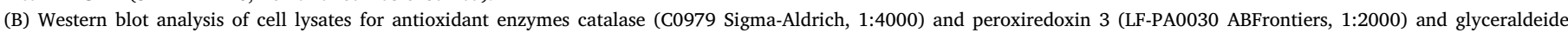

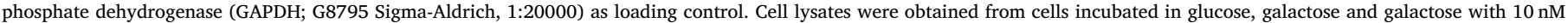
rotenone media for $24 \mathrm{~h}$.

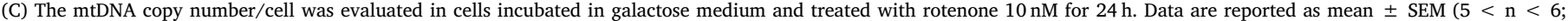
$\left.{ }^{* * * *} p<0,001 ;{ }^{* *} 0,001<p<0,01\right)$.

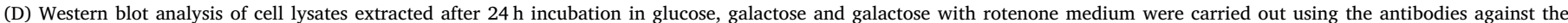

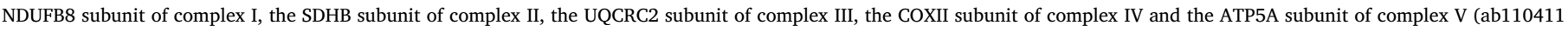
ABCAM, Total OXPHOS Human antibody cocktail 1:1000). 
A

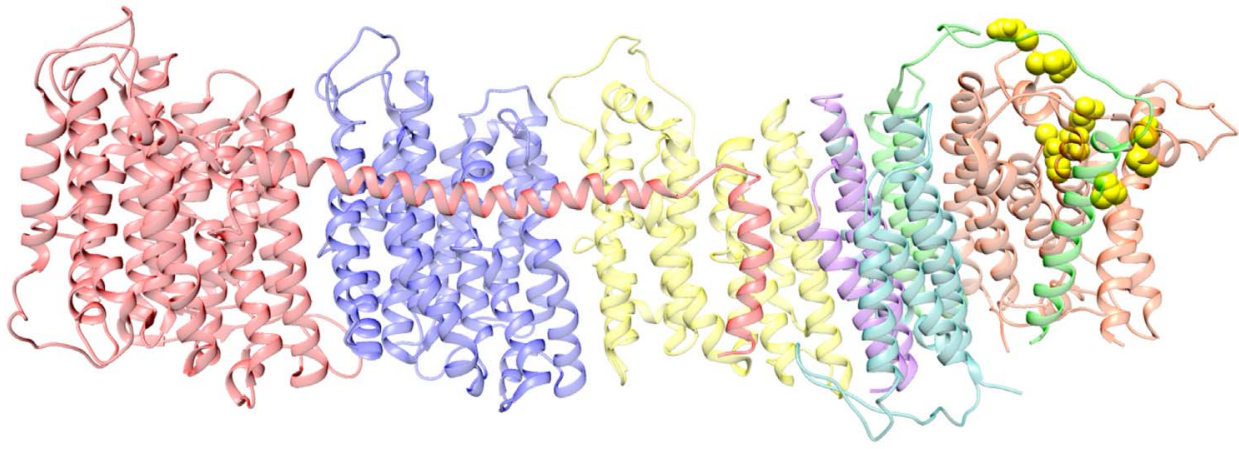

Fig. 5. Complex I model.

Localization of polymorphic variants on the crystallographic structure of the ovine complex I (Fiedorczuk et al. 2016) using the UCSF Chimera software. The structures of ND1, ND2, ND3, ND4, ND4L, ND5 and ND6 subunits are shown as ribbons, in orange, yellow, purple, blue, cyan, red and green, respectively. The combination of variants in haplogroup $\mathrm{H}$ (A), haplogroup J1 (B) and haplogroup K1 (C) are displayed as front views. The ovine amino acids His304 (corresponding to human p.Y304H, m.4216T > C/MT-ND1), Thr114 (corresponding to human p.T114A, m.10398G > A/MT-ND3) and Leu458 (corresponding to human p.A458T, m.13708G > A/MT-ND5) are shown as red-labelled spheres; whereas the key residues for $\mathrm{Q}$ cavity are shown as yellow spheres (Fiedorczuk et al. 2016). (For interpretation of the references to color in this figure legend, the reader is referred to the web version of this article.)
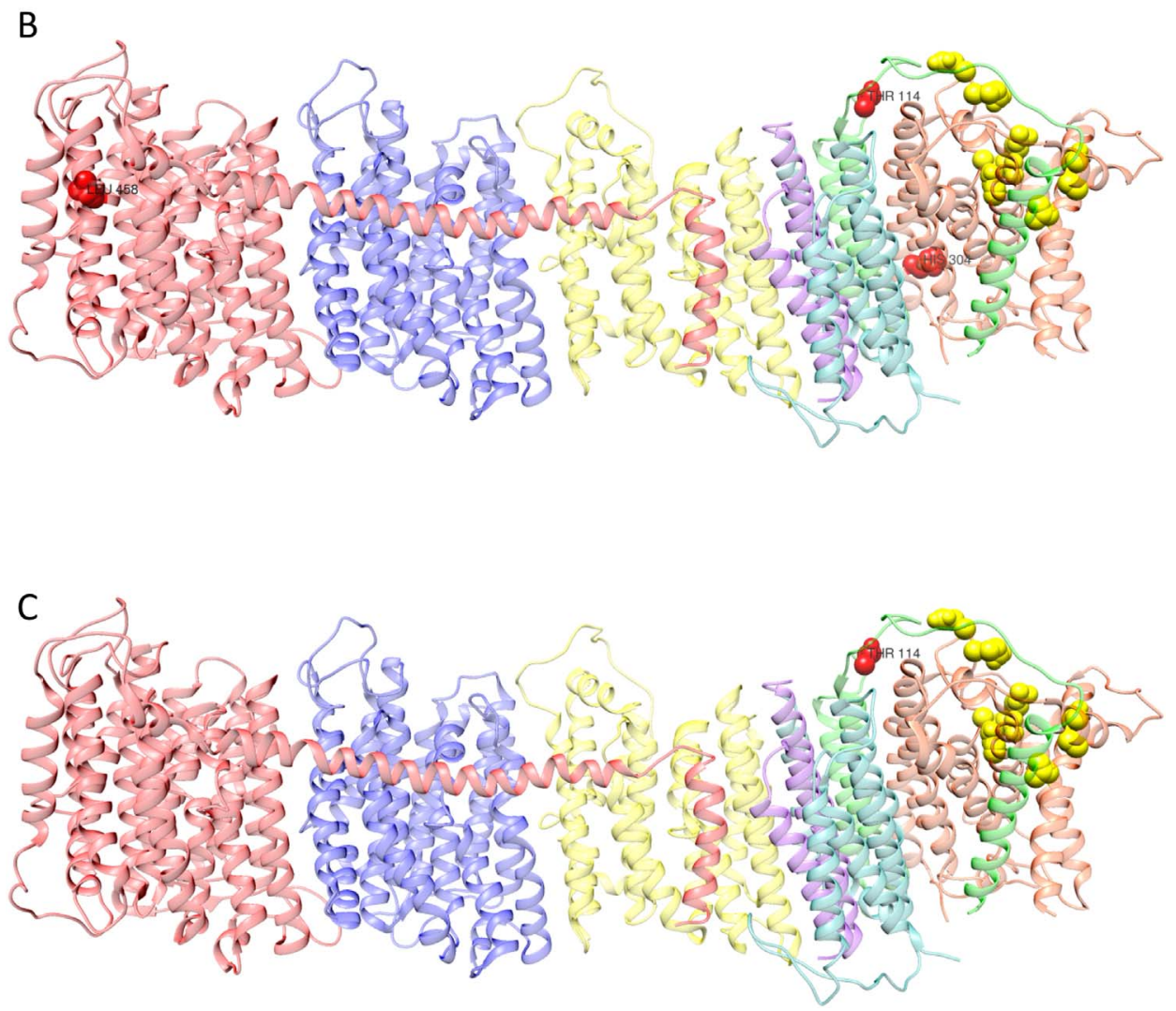

support that haplogroup J1 impinges on Complex I efficiency, given that rotenone affects complex I redox activity by interacting with the CoQ binding site, now recognized as located at the heel of complex I structure where the Q cavity extends from the hydrophilic matrix arm within the mtDNA-encoded ND1 subunit (Fiedorczuk et al. 2016). Thus, most probably the interaction of LHON Complex I pathogenic mutations with the background of haplogroup $\mathrm{J}$, which is characterized by missense variants affecting both complex I and III, has subtle functional consequences, as highlighted by the rotenone challenge, that they did not apparently affect oxygen consumption, but ultimately reflected on cell viability, under conditions of forced OXPHOS in galactose medium. In this respect, we failed to fully reproduce the results reported by Gomez-Duran and colleagues (Gómez-Durán et al. 2010), who in a larger set of cybrid clones carrying various combinations of J1c, J1b and $\mathrm{J} 2$ mitogenomes detected a lower oxygen consumption, a reduced membrane potential, and a slightly reduced mtDNA copy number compared with $\mathrm{H}$ cybrids grown in glucose medium. On the contrary, we showed that in galactose medium haplogroup $\mathrm{J} 1$ is able to further activate respiration, indicating the higher reliance on OXPHOS and, consequently, making cells more sensitive to the rotenone effect. Relevantly, when we assessed mtDNA copy number in blood cells from living LHON patients, we failed to distinguish haplogroup $\mathrm{J}$ patients from those carrying mitogenomes belonging to other haplogroups, in particular H (Giordano et al. 2014). Similarly, also the MR spectroscopy evaluation of LHON patients failed to detect functional differences in haplogroup J patients compared to non-J (Lodi et al. 2000). The striking and significant difference in mtDNA copy number was only detected between LHON affected and unaffected mutation carriers (Giordano et al. 2014), indicating a stronger effect overshadowing the haplogroup effect, presumably determined by the nuclear genetic background, which is abolished in the cybrid studies. One possibility reconciling the true relevance of haplogoup J in LHON, which needs to 
be further tested, is the interaction with environmental factors. In this study, we found that haplogroup J, without LHON mutations, is the most sensitive in term of cell viability, once cybrids are challenged with the Complex I inhibitor rotenone. Similarly, haplogroup J associated with LHON mutations (fibroblasts and cybrids) was the most sensitive to challenge with the 2,5-hexanedione and toluene toxins (Ghelli et al. 2009). Switching from in vitro conditions to in vivo this might become relevant for LHON associated with tobacco and alcohol exposure, two confirmed disease triggers (Kirkman et al. 2009; Giordano et al. 2015; Carelli et al. 2016). Overall, our results and those from Gomez-Duran and colleagues (Gómez-Durán et al. 2010) both support the scenario that the background of haplogroup $\mathrm{J}$ has, to some degree, functional consequences that enhance the pathogenic effect of the LHON primary mutation, or interact with environmental factors, resulting in an increased disease penetrance.

Interestingly, our results pointing to haplogroup $\mathrm{J}$ as the most sensitive to rotenone do not fit with the scenario of PD as a neurodegenerative age-related disorder also associated with a partially reduced Complex I activity (Giannoccaro et al. 2017). However, our results congruently highlight on the functional ground the previously reported genetic association of PD with haplogroup $\mathrm{K}$, as a protective factor. In fact, the most relevant result is the significant propensity of haplogroup $\mathrm{K}$ to set the highest mtDNA copy number in conditions of forced OXPHOS, which persists after rotenone challenge. This may indicate an efficient signaling promoting a compensatory strategy, which in turn is reflected in the lowest production of hydrogen peroxide, indicating that oxidative stress is mitigated in this mtDNA background. In fact, PRX3 was consistently highly expressed also in glucose. Conversely, the lack of a clear reflection of high mtDNA amount in haplogroup $\mathrm{K}$ with the expression of representative respiratory chain subunits might just depend on the complex post-transcriptional fine-tuning of OXPHOS. The finding of highest mtDNA amount in haplogroup $\mathrm{K}$ is particularly relevant considering the recent multiple evidences that partial depletion of mtDNA characterizes both dopaminergic neurons in substantia nigra, the target tissue of PD (Dölle et al. 2016; Grünewald et al. 2016), and peripheral blood cells (Pyle et al. 2016). It has been suggested that the age-dependent compensatory increase of mtDNA copy number characterizing normal subjects does not occur in PD patients (Dölle et al. 2016), thus determining a condition of relative mtDNA depletion cooccurring with clonally expanded mtDNA deletions in the dopaminergic neurons (Bender et al. 2006; Kraytsberg et al. 2006). Ultimately, our results provide an in vitro confirmation of the potentially protective role exerted by haplogroup K background, which was documented purely on the genetic ground by association studies (Ghezzi et al. 2005), and their metanalysis (Hudson et al. 2013). The same metanalysis also indicated haplogroups $\mathrm{J}$ and $\mathrm{T}$ as protective, which contrasts with the current functional results in cybrids. Cybrid studies and genetic associations are not necessarily directly comparable, given the addition of the nuclear genome and environmental factors in living patients on whom the association studies are performed. One possible factor partially resolving these contrasting observations is represented by the mtDNA haplogroup-mediated effect on longevity, the most relevant risk factor for age-related neurodegenerative disorders such as Parkinson and Alzheimer disease. Thus, some of the paradoxes that derive from haplogroup association studies are deeply influenced by others, more powerful modifying factors, that depending on the setting might be agerelated, or due to environmental interactions, to specific nuclear-mitochondrial interactions, and to recent private mtDNA mutations.

In conclusion, by using normal mtDNA genomes transferred within the cybrid host, we highlighted that the mtDNA sequence variation of different haplogroups and specific genomes carrying private variants may be relevant for the efficiency of mitochondrial function, under different conditions of OXPHOS activation (galactose) or inhibition (rotenone). Our results lend support to some of the genetic associations previously consolidated by multiple studies, in particular those modulating two diseases (LHON and PD) where Complex I dysfunction is implicated.

Supplementary data to this article can be found online at https:// doi.org/10.1016/j.nbd.2018.02.010.

\section{Acknowledgments}

We are deeply indebted to all healthy donors of fibroblasts for participating in this project.

\section{Funding}

This study was supported by the Italian Ministry of Health (Ricerca Corrente 2014-2016).

\section{References}

Andrews, R.M., Kubacka, I., Chinnery, P.F., Lightowlers, R.N., Turnbull, D.M., Howell, N., 1999. Reanalysis and revision of the Cambridge reference sequence for human mitochondrial DNA. Nat. Genet. 23, 147. http://dx.doi.org/10.1038/13779.

Bender, A., Krishnan, K.J., Morris, C.M., Taylor, G.A., Reeve, A.K., Perry, R.H., Jaros, E., Hersheson, J.S., Betts, J., Klopstock, T., Taylor, R.W., Turnbull, D.M., 2006. High levels of mitochondrial DNA deletions in substantia nigra neurons in aging and Parkinson disease. Nat. Genet. 38, 515-517. http://dx.doi.org/10.1038/ng1769.

Betarbet, R., Sherer, T.B., MacKenzie, G., Garcia-Osuna, M., Panov, A.V., Greenamyre, J.T., 2000. Chronic systemic pesticide exposure reproduces features of Parkinson's disease. Nat. Neurosci. 3, 1301-1306. http://dx.doi.org/10.1038/81834.

Bradford, M.M., 1976. A rapid and sensitive method for the quantitation of microgram quantities of protein utilizing the principle of protein-dye binding. Anal. Biochem. 72, $248-254$.

Calvo, S.E., Clauser, K.R., Mootha, V.K., 2016. MitoCarta2.0: an updated inventory of mammalian mitochondrial proteins. Nucleic Acids Res. 44, D1251-D1257. http://dx doi.org/10.1093/nar/gkv1003.

Carelli, V., Chan, D.C., 2014. Mitochondrial DNA: impacting central and peripheral nervous systems. Neuron 84, 1126-1142. http://dx.doi.org/10.1016/j.neuron.2014. 11.022.

Carelli, V., Ross-Cisneros, F.N., Sadun, A.A., 2004. Mitochondrial dysfunction as a cause of optic neuropathies. Prog. Retin. Eye Res. 23, 53-89. http://dx.doi.org/10.1016/j. preteyeres.2003.10.003.

Carelli, V., Achilli, A., Valentino, M.L., Rengo, C., Semino, O., Pala, M., Olivieri, A., Mattiazzi, M., Pallotti, F., Carrara, F., Zeviani, M., Leuzzi, V., Carducci, C., Valle, G., Simionati, B., Mendieta, L., Salomao, S., Belfort, R., Sadun, A.A., Torroni, A., 2006. Haplogroup effects and recombination of mitochondrial DNA: novel clues from the analysis of Leber hereditary optic neuropathy pedigrees. Am. J. Hum. Genet. 78, 564-574. http://dx.doi.org/10.1086/501236.

Carelli, V., d'Adamo, P., Valentino, M.L., La Morgia, C., Ross-Cisneros, F.N., Caporali, L., Maresca, A., Loguercio Polosa, P., Barboni, P., De Negri, A., Sadun, F., Karanjia, R., Salomao, S.R., Berezovsky, A., Chicani, F., Moraes, M., Moraes Filho, M., Belfort, R., Sadun, A.A., 2016. Parsing the differences in affected with LHON: genetic versus environmental triggers of disease conversion. Brain J. Neurol. 139, e17. http://dx doi.org/10.1093/brain/awv339.

De Benedictis, G., Rose, G., Carrieri, G., De Luca, M., Falcone, E., Passarino, G., Bonafe, M., Monti, D., Baggio, G., Bertolini, S., Mari, D., Mattace, R., Franceschi, C., 1999. Mitochondrial DNA inherited variants are associated with successful aging and longevity in humans. FASEB J. Off. Publ. Fed. Am. Soc. Exp. Biol. 13, 1532-1536.

Degli Esposti, M., 1998. Inhibitors of NADH-ubiquinone reductase: an overview. Biochim. Biophys. Acta 1364, 222-235.

DiMauro, S., Schon, E.A., Carelli, V., Hirano, M., 2013. The clinical maze of mitochondrial neurology. Nat. Rev. Neurol. 9, 429-444. http://dx.doi.org/10.1038/nrneurol.2013. 126.

Divakaruni, A.S., Paradyse, A., Ferrick, D.A., Murphy, A.N., Jastroch, M., 2014. Analysis and interpretation of microplate-based oxygen consumption and $\mathrm{pH}$ data. Methods Enzymol. 547, 309-354. http://dx.doi.org/10.1016/B978-0-12-801415-8.00016-3.

Dölle, C., Flønes, I., Nido, G.S., Miletic, H., Osuagwu, N., Kristoffersen, S., Lilleng, P.K., Larsen, J.P., Tysnes, O.-B., Haugarvoll, K., Bindoff, L.A., Tzoulis, C., 2016. Defective mitochondrial DNA homeostasis in the substantia nigra in Parkinson disease. Nat. Commun. 7, 13548. http://dx.doi.org/10.1038/ncomms13548.

Fiedorczuk, K., Letts, J.A., Degliesposti, G., Kaszuba, K., Skehel, M., Sazanov, L.A., 2016. Atomic structure of the entire mammalian mitochondrial complex I. Nature 538, 406-410. http://dx.doi.org/10.1038/nature19794.

Floreani, M., Napoli, E., Martinuzzi, A., Pantano, G., De Riva, V., Trevisan, R., Bisetto, E., Valente, L., Carelli, V., Dabbeni-Sala, F., 2005. Antioxidant defences in cybrids harboring mtDNA mutations associated with Leber's hereditary optic neuropathy: antioxidant defences in LHON cybrids. FEBS J. 272, 1124-1135. http://dx.doi.org/10. 1111/j.1742-4658.2004.04542.x.

Ghelli, A., Zanna, C., Porcelli, A.M., Schapira, A.H.V., Martinuzzi, A., Carelli, V., Rugolo, M., 2003. Leber's hereditary optic neuropathy (LHON) pathogenic mutations induce mitochondrial-dependent apoptotic death in transmitochondrial cells incubated with galactose medium. J. Biol. Chem. 278, 4145-4150. http://dx.doi.org/10.1074/jbc. M210285200.

Ghelli, A., Porcelli, A.M., Zanna, C., Vidoni, S., Mattioli, S., Barbieri, A., Iommarini, L., Pala, M., Achilli, A., Torroni, A., Rugolo, M., Carelli, V., 2009. The background of 
mitochondrial DNA Haplogroup J increases the sensitivity of Leber's hereditary optic neuropathy cells to 2,5-Hexanedione toxicity. PLoS One 4, e7922. http://dx.doi.org/ 10.1371/journal.pone.0007922.

Ghezzi, D., Marelli, C., Achilli, A., Goldwurm, S., Pezzoli, G., Barone, P., Pellecchia, M.T., Stanzione, P., Brusa, L., Bentivoglio, A.R., Bonuccelli, U., Petrozzi, L., Abbruzzese, G., Marchese, R., Cortelli, P., Grimaldi, D., Martinelli, P., Ferrarese, C., Garavaglia, B. Sangiorgi, S., Carelli, V., Torroni, A., Albanese, A., Zeviani, M., 2005. Mitochondrial DNA haplogroup $\mathrm{K}$ is associated with a lower risk of Parkinson's disease in Italians. Eur. J. Hum. Genet. EJHG 13, 748-752. http://dx.doi.org/10.1038/sj.ejhg.5201425.

Giannoccaro, M.P., La Morgia, C., Rizzo, G., Carelli, V., 2017. Mitochondrial DNA and primary mitochondrial dysfunction in Parkinson's disease. MT DNA AND PD. Mov. Disord. 32, 346-363. http://dx.doi.org/10.1002/mds.26966.

Giordano, C., Iommarini, L., Giordano, L., Maresca, A., Pisano, A., Valentino, M.L., Caporali, L., Liguori, R., Deceglie, S., Roberti, M., Fanelli, F., Fracasso, F., RossCisneros, F.N., D'Adamo, P., Hudson, G., Pyle, A., Yu-Wai-Man, P., Chinnery, P.F., Zeviani, M., Salomao, S.R., Berezovsky, A., Belfort, R., Ventura, D.F., Moraes, M., Moraes Filho, M., Barboni, P., Sadun, F., De Negri, A., Sadun, A.A., Tancredi, A., Mancini, M., d'Amati, G., Loguercio Polosa, P., Cantatore, P., Carelli, V., 2014. Efficient mitochondrial biogenesis drives incomplete penetrance in Leber's hereditary optic neuropathy. Brain J. Neurol. 137, 335-353. http://dx.doi.org/10.1093/brain/ awt343.

Giordano, L., Deceglie, S., d'Adamo, P., Valentino, M.L., La Morgia, C., Fracasso, F., Roberti, M., Cappellari, M., Petrosillo, G., Ciaravolo, S., Parente, D., Giordano, C., Maresca, A., Iommarini, L., Del Dotto, V., Ghelli, A.M., Salomao, S.R., Berezovsky, A., Belfort, R., Sadun, A.A., Carelli, V., Loguercio Polosa, P., Cantatore, P., 2015. Cigarette toxicity triggers Leber's hereditary optic neuropathy by affecting mtDNA copy number, oxidative phosphorylation and ROS detoxification pathways. Cell Death Dis. 6, e2021. http://dx.doi.org/10.1038/cddis.2015.364.

Giorgio, V., Petronilli, V., Ghelli, A., Carelli, V., Rugolo, M., Lenaz, G., Bernardi, P., 2012. The effects of idebenone on mitochondrial bioenergetics. Biochim. Biophys. Acta BBA Bioenerg. 1817, 363-369. http://dx.doi.org/10.1016/j.bbabio.2011.10.012.

Gómez-Durán, A., Pacheu-Grau, D., López-Gallardo, E., Díez-Sánchez, C., Montoya, J., López-Pérez, M.J., Ruiz-Pesini, E., 2010. Unmasking the causes of multifactorial disorders: OXPHOS differences between mitochondrial haplogroups. Hum. Mol. Genet. 19, 3343-3353. http://dx.doi.org/10.1093/hmg/ddq246.

Gómez-Durán, A., Pacheu-Grau, D., Martínez-Romero, Í., López-Gallardo, E., López-Pérez, M.J., Montoya, J., Ruiz-Pesini, E., 2012. Oxidative phosphorylation differences between mitochondrial DNA haplogroups modify the risk of Leber's hereditary optic neuropathy. Biochim. Biophys. Acta (BBA) - Mol. Basis Dis. 1822, 1216-1222. http:// dx.doi.org/10.1016/j.bbadis.2012.04.014.

Grünewald, A., Rygiel, K.A., Hepplewhite, P.D., Morris, C.M., Picard, M., Turnbull, D.M., 2016. Mitochondrial DNA depletion in respiratory chain-deficient Parkinson disease neurons. Ann. Neurol. 79, 366-378. http://dx.doi.org/10.1002/ana.24571.

Gustafsson, C.M., Falkenberg, M., Larsson, N.-G., 2016. Maintenance and expression of mammalian mitochondrial DNA. Annu. Rev. Biochem. 85, 133-160. http://dx. doi. org/10.1146/annurev-biochem-060815-014402.

Hudson, G., Carelli, V., Spruijt, L., Gerards, M., Mowbray, C., Achilli, A., Pyle, A., Elson, J., Howell, N., La Morgia, C., Valentino, M.L., Huoponen, K., Savontaus, M.-L., Nikoskelainen, E., Sadun, A.A., Salomao, S.R., Belfort, R., Griffiths, P., Man, P.Y.W., de Coo, R.F.M., Horvath, R., Zeviani, M., Smeets, H.J.T., Torroni, A., Chinnery, P.F., 2007. Clinical expression of Leber hereditary optic neuropathy is affected by the mitochondrial DNA-Haplogroup background. Am. J. Hum. Genet. 81, 228-233. http://dx.doi.org/10.1086/519394.

Hudson, G., Nalls, M., Evans, J.R., Breen, D.P., Winder-Rhodes, S., Morrison, K.E., Morris, H.R., Williams-Gray, C.H., Barker, R.A., Singleton, A.B., Hardy, J., Wood, N.E., Burn, D.J., Chinnery, P.F., 2013. Two-stage association study and meta-analysis of mitochondrial DNA variants in Parkinson disease. Neurology 80, 2042-2048. http://dx. doi.org/10.1212/WNL.0b013e318294b434.

King, M.P., Attardi, G., 1989. Human cells lacking mtDNA: repopulation with exogenous mitochondria by complementation. Science 246, 500-503.

King, M.P., Attardi, G., 1996. Isolation of human cell lines lacking mitochondrial DNA. Methods Enzymol. 264, 304-313.

Kirkman, M.A., Yu-Wai-Man, P., Korsten, A., Leonhardt, M., Dimitriadis, K., De Coo, I.F., Klopstock, T., Chinnery, P.F., 2009. Gene-environment interactions in Leber hereditary optic neuropathy. Brain J. Neurol. 132, 2317-2326. http://dx.doi.org/10.1093/ brain/awp158.

Koopman, W.J.H., Nijtmans, L.G.J., Dieteren, C.E.J., Roestenberg, P., Valsecchi, F., Smeitink, J.A.M., Willems, P.H.G.M., 2010. Mammalian mitochondrial complex I: biogenesis, regulation, and reactive oxygen species generation. Antioxid. Redox Signal. 12, 1431-1470. http://dx.doi.org/10.1089/ars.2009.2743.

Kraytsberg, Y., Kudryavtseva, E., McKee, A.C., Geula, C., Kowall, N.W., Khrapko, K., 2006. Mitochondrial DNA deletions are abundant and cause functional impairment in aged human substantia nigra neurons. Nat. Genet. 38, 518-520. http://dx.doi.org/ $10.1038 / \mathrm{ng} 1778$.

Larsson, N.-G., 2010. Somatic mitochondrial DNA mutations in mammalian aging. Annu. Rev. Biochem. 79, 683-706. http://dx.doi.org/10.1146/annurev-biochem-060408093701.

Lodi, R., Montagna, P., Cortelli, P., Iotti, S., Cevoli, S., Carelli, V., Barbiroli, B., 2000 "Secondary" 4216/ND1 and 13708/ND5 Leber's hereditary optic neuropathy mitochondrial DNA mutations do not further impair in vivo mitochondrial oxidative metabolism when associated with the 11778/ND4 mitochondrial DNA mutation. Brain J. Neurol. 123 (Pt 9), 1896-1902.

Manfredi, G., Yang, L., Gajewski, C.D., Mattiazzi, M., 2002. Measurements of ATP in mammalian cells. Methods San Diego Calif 26, 317-326. http://dx.doi.org/10.1016/ S1046-2023(02)00037-3.

Marella, M., Seo, B.B., Thomas, B.B., Matsuno-Yagi, A., Yagi, T., 2010. Successful amelioration of mitochondrial optic neuropathy using the yeast NDI1 gene in a rat animal model. PLoS One 5, e11472. http://dx.doi.org/10.1371/journal.pone. 0011472.

Mishmar, D., Ruiz-Pesini, E., Golik, P., Macaulay, V., Clark, A.G., Hosseini, S., Brandon, M., Easley, K., Chen, E., Brown, M.D., Sukernik, R.I., Olckers, A., Wallace, D.C., 2003. Natural selection shaped regional mtDNA variation in humans. Proc. Natl. Acad. Sci. 100, 171-176. http://dx.doi.org/10.1073/pnas.0136972100.

Moreno-Loshuertos, R., Acín-Pérez, R., Fernández-Silva, P., Movilla, N., Pérez-Martos, A. Rodriguez de Cordoba, S., Gallardo, M.E., Enríquez, J.A., 2006. Differences in reactive oxygen species production explain the phenotypes associated with common mouse mitochondrial DNA variants. Nat. Genet. 38, 1261-1268. http://dx.doi.org/ 10.1038/ng1897.

Mussini, C., Pinti, M., Bugarini, R., Borghi, V., Nasi, M., Nemes, E., Troiano, L., Guaraldi, G., Bedini, A., Sabin, C., Esposito, R., Cossarizza, A., 2005. Effect of treatment interruption monitored by CD4 cell count on mitochondrial DNA content in HIV-infected patients: a prospective study. AIDS Lond. Engl. 19, 1627-1633.

van Oven, M., Kayser, M., 2009. Updated comprehensive phylogenetic tree of global human mitochondrial DNA variation. Hum. Mutat. 30, E386-E394. http://dx.doi. org/10.1002/humu.20921.

Pala, M., Olivieri, A., Achilli, A., Accetturo, M., Metspalu, E., Reidla, M., Tamm, E. Karmin, M., Reisberg, T., Kashani, B.H., Perego, U.A., Carossa, V., Gandini, F., Pereira, J.B., Soares, P., Angerhofer, N., Rychkov, S., Al-Zahery, N., Carelli, V., Sanati, M.H., Houshmand, M., Hatina, J., Macaulay, V., Pereira, L., Woodward, S.R., Davies, W., Gamble, C., Baird, D., Semino, O., Villems, R., Torroni, A., Richards, M.B., 2012. Mitochondrial DNA signals of late glacial recolonization of Europe from near Eastern Refugia. Am. J. Hum. Genet. 90, 915-924. http://dx.doi.org/10.1016/j.ajhg. 2012.04.003.

Payne, B.A.I., Wilson, I.J., Yu-Wai-Man, P., Coxhead, J., Deehan, D., Horvath, R., Taylor, R.W., Samuels, D.C., Santibanez-Koref, M., Chinnery, P.F., 2013. Universal heteroplasmy of human mitochondrial DNA. Hum. Mol. Genet. 22, 384-390. http://dx.doi. org $/ 10.1093 / \mathrm{hmg} / \mathrm{dds} 435$.

Pello, R., Martín, M.A., Carelli, V., Nijtmans, L.G., Achilli, A., Pala, M., Torroni, A., Gómez-Durán, A., Ruiz-Pesini, E., Martinuzzi, A., Smeitink, J.A., Arenas, J., Ugalde, C., 2008. Mitochondrial DNA background modulates the assembly kinetics of OXPHOS complexes in a cellular model of mitochondrial disease. Hum. Mol. Genet. 17, 4001-4011. http://dx.doi.org/10.1093/hmg/ddn303.

Porcelli, A.M., Ghelli, A., Ceccarelli, C., Lang, M., Cenacchi, G., Capristo, M., Pennisi, L.F., Morra, I., Ciccarelli, E., Melcarne, A., Bartoletti-Stella, A., Salfi, N., Tallini, G., Martinuzzi, A., Carelli, V., Attimonelli, M., Rugolo, M., Romeo, G., Gasparre, G., 2010. The genetic and metabolic signature of oncocytic transformation implicates HIF1 destabilization. Hum. Mol. Genet. 19, 1019-1032. http://dx.doi.org/10.1093/ hmg/ddp566.

Pyle, A., Anugrha, H., Kurzawa-Akanbi, M., Yarnall, A., Burn, D., Hudson, G., 2016. Reduced mitochondrial DNA copy number is a biomarker of Parkinson's disease. Neurobiol. Aging 38 (216.e7-216.e10). https://doi.org/10.1016/j.neurobiolaging. 2015.10.033.

Raule, N., Sevini, F., Santoro, A., Altilia, S., Franceschi, C., 2007. Association studies on human mitochondrial DNA: methodological aspects and results in the most common age-related diseases. Mitochondrion 7, 29-38. http://dx.doi.org/10.1016/j.mito. 2006.11.013.

Robinson, B.H., 1996. Use of fibroblast and lymphoblast cultures for detection of respiratory chain defects. Methods Enzymol. 264, 454-464.

Ruiz-Pesini, E., 2004. Effects of purifying and adaptive selection on regional variation in human mtDNA. Science 303, 223-226. http://dx.doi.org/10.1126/science.1088434.

Ruiz-Pesini, E., Lott, M.T., Procaccio, V., Poole, J.C., Brandon, M.C., Mishmar, D., Yi, C. Kreuziger, J., Baldi, P., Wallace, D.C., 2007. An enhanced MITOMAP with a global mtDNA mutational phylogeny. Nucleic Acids Res. 35, D823-D828. http://dx.doi.org/ 10.1093/nar/gk1927.

Samuels, D.C., Carothers, A.D., Horton, R., Chinnery, P.F., 2006. The power to detect disease associations with mitochondrial DNA Haplogroups. Am. J. Hum. Genet. 78, 713-720. http://dx.doi.org/10.1086/502682

Scarlatti, F., Sala, G., Somenzi, G., Signorelli, P., Sacchi, N., Ghidoni, R., 2003. Resveratrol induces growth inhibition and apoptosis in metastatic breast cancer cells via de novo ceramide signaling. FASEB J. Off. Publ. Fed. Am. Soc. Exp. Biol. 17, 2339-2341. http://dx.doi.org/10.1096/fj.03-0292fje.

Schon, E.A., DiMauro, S., Hirano, M., 2012. Human mitochondrial DNA: roles of inherited and somatic mutations. Nat. Rev. Genet. 13, 878-890. http://dx.doi.org/10.1038/ nrg3275.

Soares, P., Achilli, A., Semino, O., Davies, W., Macaulay, V., Bandelt, H.-J., Torroni, A., Richards, M.B., 2010. The archaeogenetics of Europe. Curr. Biol. 20, R174-R183. http://dx.doi.org/10.1016/j.cub.2009.11.054.

Stewart, J.B., Chinnery, P.F., 2015. The dynamics of mitochondrial DNA heteroplasmy: implications for human health and disease. Nat. Rev. Genet. 16, 530-542. http://dx. doi.org/10.1038/nrg3966.

Torroni, A., Petrozzi, M., D'Urbano, L., Sellitto, D., Zeviani, M., Carrara, F., Carducci, C., Leuzzi, V., Carelli, V., Barboni, P., De Negri, A., Scozzari, R., 1997. Haplotype and phylogenetic analyses suggest that one European-specific mtDNA background plays a role in the expression of Leber hereditary optic neuropathy by increasing the penetrance of the primary mutations 11778 and 14484 . Am. J. Hum. Genet. 60, $1107-1121$.

Torroni, A., Rengo, C., Guida, V., Cruciani, F., Sellitto, D., Coppa, A., Calderon, F.L., Simionati, B., Valle, G., Richards, M., Macaulay, V., Scozzari, R., 2001. Do the four clades of the mtDNA haplogroup L2 evolve at different rates? Am. J. Hum. Genet. 69, 1348-1356. http://dx.doi.org/10.1086/324511.

Trounce, I.A., Kim, Y.L., Jun, A.S., Wallace, D.C., 1996. Assessment of mitochondrial oxidative phosphorylation in patient muscle biopsies, lymphoblasts, and 
transmitochondrial cell lines. Methods Enzymol. 264, 484-509.

Vigilant, L., Stoneking, M., Harpending, H., Hawkes, K., Wilson, A.C., 1991. African populations and the evolution of human mitochondrial DNA. Science 253, 1503-1507.

Wallace, D.C., 2013. Bioenergetics in human evolution and disease: implications for the origins of biological complexity and the missing genetic variation of common diseases. Philos. Trans. R. Soc. B Biol. Sci. 368, 20120267. http://dx.doi.org/10.1098/ rstb.2012.0267.
Wallace, D.C., 2015. Mitochondrial DNA variation in human radiation and disease. Cell 163, 33-38. http://dx.doi.org/10.1016/j.cell.2015.08.067.

Wu, M., Neilson, A., Swift, A.L., Moran, R., Tamagnine, J., Parslow, D., Armistead, S. Lemire, K., Orrell, J., Teich, J., Chomicz, S., Ferrick, D.A., 2007. Multiparameter metabolic analysis reveals a close link between attenuated mitochondrial bioenergetic function and enhanced glycolysis dependency in human tumor cells. Am. J. Phys. Cell Phys. 292, C125-136. http://dx.doi.org/10.1152/ajpcell.00247.2006. 